\title{
Organophosphorus poisoning at a chemical packaging company
}

\author{
R D JONES \\ Epidemiological and Medical Statistics Unit, Health and Safety Executive, London W2 4TF, UK
}

ABSTRACT Six men packaging demeton-S-methyl concentrate developed organophosphorous poisoning. An account of the circumstances of the occurrence is given, together with the results of an investigation into the incidents. The clinical cases are described in outline and individual response to absorption of the pesticide considered. Some relevant issues on the use of protective clothing when working with organophosphorous compounds are discussed.

Demeton-S-methyl is an organophosphorous compound that has been used commercially as a pesticide for well over 20 years. The pesticide is manufactured in Britain but, as in this case, some is produced abroad and imported in bulk. Despite its low volatility (boiling point $89^{\circ} \mathrm{C}$ ) it has a nauseating smell. It is used as a pesticide treatment for crops and is produced dissolved in xylene as a concentrate. The concentrate referred to in this paper contained $500 \mathrm{~g}$ of demeton-S-methyl per litre. Before application to the crop this would be diluted some one hundred to a thousand times with water.

\section{Circumstances of incident}

A chemical packaging company contracted to pack a bulk load of demeton-S-methyl concentrate into one-litre containers. The work was carried out using a weight-triggered bottle-filling machine, one worker filling the cans while a second fitted a seal and top (workers A and B). Further workers then labelled and packed the cans. Workers $A$ and $B$ rotated jobs, and the operation was carried out in an open yard. Gloves, overalls, and boots were worn, but there was frequent spillage and items of normal clothing had been left under the filling apparatus, giving ample opportunity for contamination of after-work garments. The operation took one full working day plus a few hours of the next morning. Worker A was admitted to hospital with organophosphorous poisoning in the evening of the

Received 9 November 1981

Accepted 27 January 1982 first day and worker B some 72 hours later. The workers packing and labelling the cans had complained of the nauseating smell of the compound, but none was medically treated or had time off work.

As a result of these two cases of organophosphorous poisoning, the operation was suspended pending the design of a new system of work. Among the modifications made was the housing of the filling machine in an adequately extracted fume cupboard. The wearing of suitable protective equipment was insisted on and changing room facilities were provided, with appropriate dirty and clean areas. The protective clothing used consisted of industrial grade gloves of various types, overalls, boots, sleevelets, and face visor.

Some 17 days after the original system of work had last been used the new procedures were put into operation. (Workers A and B were still unwell and did not participate.) On the second day of working the process under these improved conditions, a third victim (worker $\mathrm{C}$, who had been fitting the infill and screw top) developed organophosphorous poisoning. The process was stopped pending further investigation.

The extraction system of the fume cupboard was tested and found to be adequate. Atmospheric samples from within the cupboard and from over a bin full of rejected cans showed no evidence of residual vapour contamination. The internal and external surfaces of the gloves used were washed with methylethylketone, and the resulting solutions analysed by gas chromatography. The presence of demeton-S-methyl was detected on the inside and outside of all the gloves used. 


\section{Clinical methods}

In addition to case history and clinical examination, blood samples were taken at various times and estimation of plasma (pseudocholinesterase) and red cell cholinesterase carried out by the electro-metric $\Delta \mathrm{pH}$ method of Michel. ${ }^{1}$ Before starting the new system of work each employee, some of whom had been packing and labelling cans under the old system, was interviewed and blood was taken. Unfortunately, work was restarted before these results were known. After suspension of the process blood was again taken from the four men concerned. Follow-up samples were taken over a period of some weeks, during which time it was ensured that further exposure to organophosphates did not occur.

\section{Clinical results}

Estimation of cholinesterase carried out on blood samples from three of the four men before operating the new system of work gave results below the lower limit of the normal range for cholinesterase activity. Blood samples taken after the new system of work had been operated showed further depression of cholinesterase in one of these three men and depression of cholinesterase in the fourth man whose previous levels had been within the normal range for cholinesterase activity.

\section{INDIVIDUAL CASES}

\section{Worker $A$}

In between carrying out other tasks this 32-year-old man spent three to four hours operating the filling machine under the original system of work. He changed his clothes and washed his hands on leaving work but began to feel sick on the way home. He felt drunk and vomited. He developed weakness, difficulty with his breathing, and diarrhoea. There

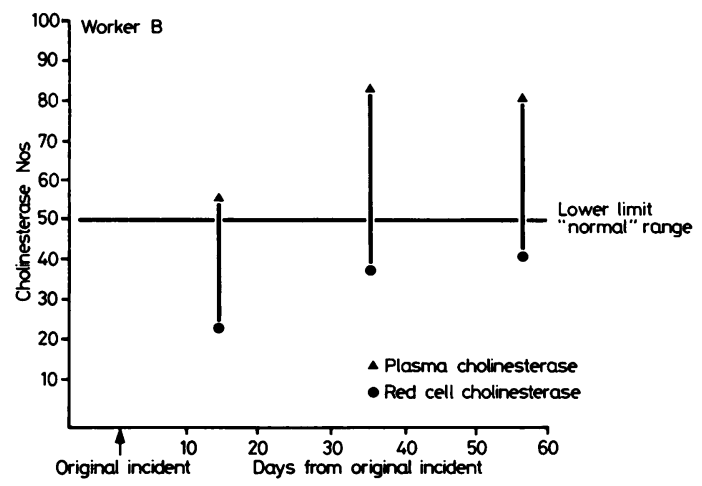

Fig 1 Worker B: cholinesterase measurements taken some 14 days after exposure. was hearsay evidence that his wife and neighbour also developed sickness and parasthesia after handling some of his clothes. On admission to hospital he was noted to be dyspnoeic and pale. His intermittent bradycardia was treated with atropine and pralidoxime. He continued to experience sweats and bradycardia for some two or three days, during which time he continued to receive intermittent intravenous atropine. He was discharged home after a week but did not return to work for some weeks. Blood taken at his home five weeks after his exposure showed his plasma cholinesterase to be 91 cholinesterase nos and his red cell activity to be 34 Che nos (normal range for plasma 50-130 Che nos; red cells 50-100 Che nos).

\section{Worker $B$}

This 27-year-old man worked at the filling machine for only about 90 minutes on the first day and started to feel giddy and unwell with some sickness the same evening. He went into work the next morning still feeling sick and unwell. He worked for an hour or two filling the remaining cans to complete the job. Over the weekend he continued to feel weak and dizzy and again became ill at work the next Monday. (By this time worker A was already in hospital and work on organophosphorous had ceased.) He collapsed that evening and was taken into casualty complaining of cramps in his legs and sweats. No abnormality was apparent clinically, but he was admitted to hospital and given atropine for relief of symptoms. Cholinesterase measurements taken some 14 days after exposure still showed considerable depression of red cell activity (fig 1 ).

\section{Worker $C$}

When first interviewed after the initial two cases, this man had no complaints. He had worked as a labeller and packer and had not been one of the original filling operators. Under the new system of work, he had spent a day fitting the infill seal and screwing on the tops. On the morning of the second day he became ill, felt sick and nauseated, and complained of abdominal cramp. He was admitted to hospital where he was given atropine intravenously for the cramps and sweats which he continued to experience. After the first 24 hours he began to recover, although he remained weak and complained of recurrent cramps. Cholinesterase results are shown in fig 2 . He had been wearing industrial gloves and protective equipment as described, but despite this and the fume cupboard precautions he experienced organophosphorous poisoning. It is clear from the results, however, that cholinesterase depression, presumably due to contact with organophosphorous, had already occurred before 


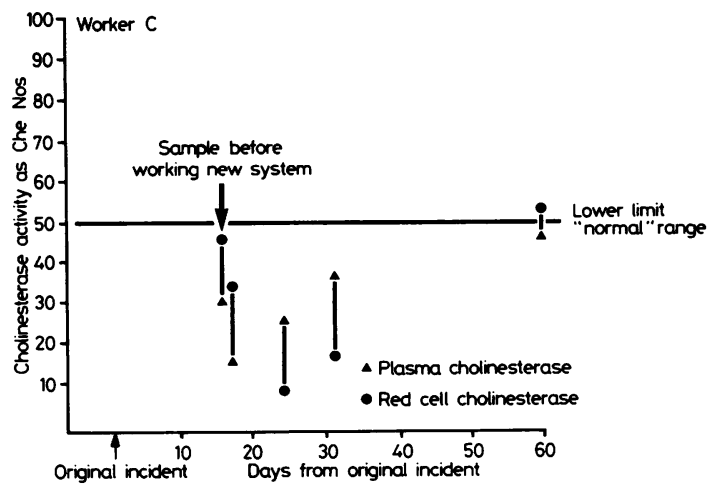

Fig 2 Worker C: cholinesterase results.

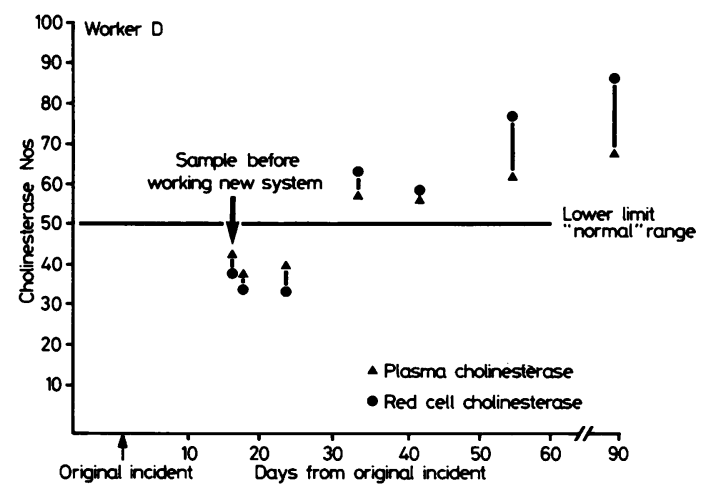

Fig 3 Worker D: cholinesterase results.

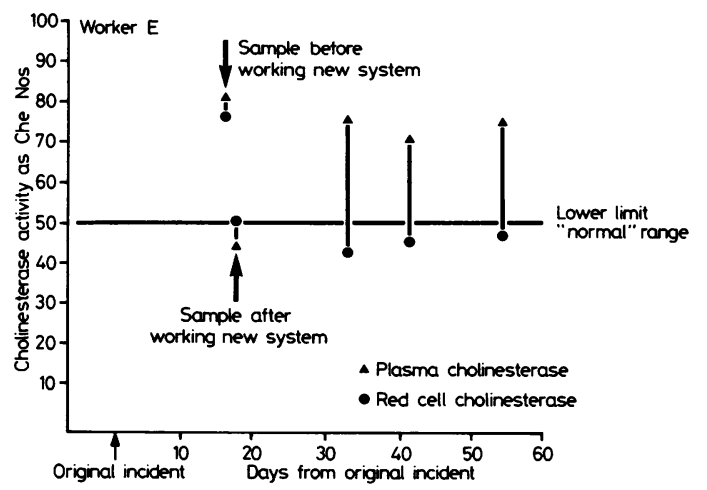

Fig 4 Worker E: cholinesterase results.

his working with the new system. His red cell cholinesterase activity was greater than his plasma cholinesterase activity before the onset of symptoms, and seven weeks after his illness red cell activity recovery had again achieved a level in excess of the plasma cholinesterase. Unfortunately, this man was lost to further follow-up so that we were unable to investigate him further. The red cell cholinesterase level of 9 Che nos recorded one week after he had become ill was the lowest found in this series of cases.

Worker $D$

This 21-year-old man had been the only filling operator on the second occasion under the improved system of work. Repeated interviews, with the knowledge of hindsight, showed that he had occasionally worked as a filler when the original system of work had been in operation. It would also appear that despite denying any symptoms at the time, he may well have had a degree of organophosphorous poisoning after working on the process a few weeks previously. He had worn heavy PVC gauntlets on the second occasion, in addition to his other protective clothing. His cholinesterase results are shown in fig 3. He did not complain of any symptoms and clinically showed no abnormality. His cholinesterase results do not show evidence of depression as a result of working the new system. The regeneration of cholinesterase activity some weeks after the incident, however, is indicative that his original cholinesterase levels were indeed depressed.

\section{Worker $E$}

This normally fit 35-year-old man had apparently supervised activities and moved the pump from each bulk drum as it became empty on to the next. For this he had worn full protective clothing as described including a pair of neoprene gloves. After one day of this process the man had begun to feel sick and unwell. He experienced abdominal cramps. On examination his pulse was a regular 72 , he was not sweating, and there was no clinical abnormality. He was off work for a few days after the incident, during which time he continued to get intermittent abdominal cramps, which resolved about five to six days later. His cholinesterase results show a sharp drop from activity within the normal range before the restarting of the work to activity just below the generally accepted lower limit of normal for plasma and red cell cholinesterase. His plasma cholinesterase showed a rapid rise over two to three weeks back to his pre-exposure level, but the red cell activity remained depressed (fig 4).

\section{Worker $F$}

On initial interview this 35-year-old man was asymptomatic. Some days after this he began to complain of weakness and generally feeling unwell with some sweats. He remained at work and his cholinesterase results are shown in fig 5 . Depression of cholinesterase activity had occurred, but there is no evidence in these results that his participation under the new system of work contributed to this. 


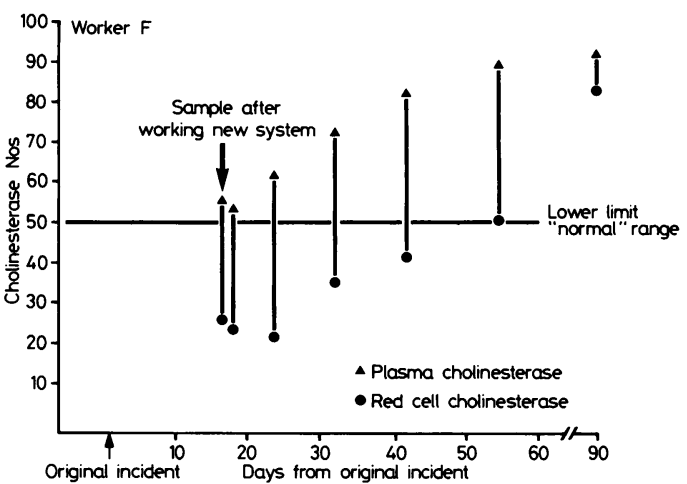

Fig 5 Worker F: cholinesterase results.

\section{Discussion and comment}

From the circumstances of these incidents, the potent toxicity of demeton-S-methyl concentrate is evident. Whereas absorption might have been expected under the original system of work, this had continued to be the case for workers $\mathrm{C}$ and $\mathrm{E}$ when a more stringent system had been introduced and despite the wearing of apparently adequate protective clothing. In all cases and on both occasions the portal of entry appeared to be the skin, and exposure occurred as a result of either inadequate wearing or penetration of the protective clothing used. All subjects were apparently fit men who showed individual variation in the levels of cholinesterase at which symptoms and signs developed.

The episode shows variation between individuals in tolerance to organophosphorous absorption. There is also a variable relationship between cholinesterase depression and clinical effect. The figures show well that red cell cholinesterase activity takes longer to become depressed and much longer to recover than the plasma enzyme. The man wearing thick PVC gloves with a good system of work was afforded greater protection than those wearing gloves of other plastic materials, but the man wearing neoprene gloves showed pronounced depression of cholinesterase activity, despite apparently only intermittent opportunity for contamination with the pesticide. This man continued to wear these gloves for a considerable time, however, so that once contamination had occurred, the opportunity for skin absorption could have continued for several hours. The period for which individuals experienced symptoms sufficient to keep them away from work in some cases ran into several weeks. Interestingly, in at least one of the cases medical advice was not sought until some time after the onset of symptoms. Depression of red cell activity appeared to correlate better with clinical effect than depression of the plasma fraction. The fact that worker $\mathrm{C}$ was originally asymptomatic with already low levels of cholinesterase, while worker E developed symptoms when his cholinesterase activity fell to just below the lower "normal" limit, suggests that the rate of fall in activity may also relate to clinical effect. The most frequent presenting symptoms of toxicity in these men appeared to be nausea, weakness, sweats, and abdominal cramps.

Xylene is known to attack rubber and plastics, and it is therefore possible for penetration of gloves by xylene to occur. The wearing of gloves, however, will still provide a measure of protection against skin absorption. The wearing of protective clothing made from various rubbers and plastics appears to be insufficient protection against demeton-S-methyl dissolved in xylene when the risk of contamination, and therefore the wearing of contaminated clothing, exists over a working period. The varying circumstances of exposure coupled with the multiplicity of glove types used at this plant prevents anything more than anecdotal comparison of the efficacy of particular glove materials.

During the use of demeton-S-methyl as an agricultural pesticide, the concentrate is used intermittently for making up a very much more dilute (usually by a factor of some 100 to 1000 times) spraying solution, which is then often applied remotely with the operator in the confines of a tractor cab or aircraft. Further need for contact with the concentrate in this case is delayed until more spraying solution has to be made up. When the risk of contamination and wearing of contaminated protective clothing occurs only intermittently in this way, it is unlikely that appreciable skin absorption would result from penetration of the gloves by pesticide concentrate because of the short time for which the gloves are worn. The operator in these circumstances is therefore afforded an adequate degree of protection from skin contact by the rubber gloves, overalls, and face shields, as recommended by Her Majesty's Agricultural Inspectorate. ${ }^{2}$ In an industrial context, however, such protection is likely to prove inadequate. Thus it would appear that where the risk of contamination occurs for any length of time manual processing may prove unsafe, and in certain conditions automated plant may be the only method by which xylene-dissolved pesticides can be safely processed. Several agrochemicals are dissolved in xylene, and this principle would clearly hold where such substances have potent toxicity by virtue of skin absorption.

This incident illustrates the well-known principle that precautions adequate for dealing with the toxic risk of a substance in one situation may not be relev- 
ant where the circumstances of the use of the substance differ.

I am grateful for the co-operation of Dr J Bamforth, Southampton General Hospital, under whose care three of these men were admitted; Mr P J Lewis of the occupational medicine and hygiene laboratories for the cholinesterase estimations; Mr P Gardner of Her Majesty's Factory Inspectorate, in association with whom this incident was investigated; and $\mathrm{Mr} \mathrm{G}$
Guerling of the occupational medicine and hygiene laboratories who carried out chemical examination of the clothing used.

\section{References}

1 Michel HO. Electro-metric method for the determination of red blood cell plasma cholinesterase activity. J Lab Clin Med 1949;34:1564-8.

2 The Health \& Safety (Agriculture) (Poisonous Substances) Regulations 1975. 